\section{KEPEMIMPINAN PENDIDIKAN BERBASIS KARAKTER}

Maimunah, S.Ag, M.Pd.I

Ketua program studi Manajemen Pendidikan Islam Fakultas Ilmu Agama Islam Universitas Islam Indragiri (UNISI) Tembilahan

\section{Abstrak}

Indonesia pasca reformasi telah mengalami krisis multidimensi, utamanya keterpurukan moral pada sektor ekonomi, politik, dan pendidikan. Peristiwa Krisis dan penyimpangan perilaku siswa yang marak diiringi sebagian kecil perilaku bermasalah guru dan kepala sekolah telah menjadi salah satu embrio lahirnya kurikulum 2013. Lahirnya kurikulum 2013 juga menjawab berbagai persoalan dan perubahan kurikulum 2006, mengembalikan basis kompetensi sesuai amanat Undang-undang Pendidikan Nasional dengan pengintegrasian pendidikan berbasis karakter. Pemimpin pendidikan turut bertanggungjawab mensukseskan implementasi kurikulum 2013 termasuk pendidikan karakter pada semua jenjang. Salah satu kunci sukses bagi pemimpin pendidikan dipersyaratkan memiliki kepribadian berbasis akhlak karimah dalam rangka menerapkan pendidikan berkarakter. Siklus dan tahapan pendidikan karakter melalui kepemimpinan pendidikan dalam proses internalisasi, personifikasi, sosialisasi dan kulturalisasi nilai-nilai moral-spiritual melalui manajemen kompetensi kepribadian menjadi kunci efektif kepemimpinan pendidikan.

Kata kunci: Kepemimpinan Pendidikan, Karakter

\section{A. Pendahuluan}

Bangsa Indonesia saat ini sedang menghadapi ujian berat yang harus dilalui, yaitu terjadinya krisis multidimensi yang berkepanjangan. Ketika negara-negara lain Thailand, Malaysia, Korea Selatan, dan lain-lain telah bangkit segera setelah mengalami krisis moneter yang melanda Asia pada 1997. Indonesia sampai saat ini tahun 2014 masih memperbaiki kondisi krisis, dan masih kelihatan suram untuk bangkit dari keterpurukan yang melanda bangsa ini.

Darmaningtyas, juga sepaham bahwa krisis moneter di Indonesia sejak Juli 1997 telah berkembang menjadi multi krisis di bidang ekonomi, politik, budaya, dan moral. Multi krisis ini telah memporak porandakan struktur kehidupan bangsa Indonesia, termasuk pendidikan nasional, setelah bidang pangan dan kesehatan. ${ }^{1}$ Namun demikian, bangsa Indonesia mencoba untuk bangkit memperbaiki keadaan, dengan berbagai upaya, misalkan dengan mendirikan KPU (Komite Pemilihan Umum) yang independen, KPK (Komite Pemberantas Korupsi) yang independen. Tentu terbentuknya lembaga-lembaga baru ini sebagai bentuk "kekurang percayaan" pada kenetralan dan kebijakan keadilan, kejujuran pemerintah dalam menjalankan reformasi dan demokratisasi.

Krisis multidimensi di Indonesia pada dasarnya mengakar pada menurunnya kualitas moral bangsa yang dicirikan oleh membudayanya praktek KKN (Korupsi, Kolusi, dan Nepotisme), konflik vertikal (konflik elit politik di tingkat nasional) dan konflik horizontal antar etnis, agama, politisi, preman, remaja, desa, antar warga, kasus perburuan, pelecehan, penganiayaan dan sebagainya, meningkatkan kriminalitas seks bebas dan pemerkosaan, perampokan, pembunuhan, penipuan, narkoba, dan sebagainya, menurunnya etos kerja, menurunnya akhlak dan moral yang mengakibatkan timbulnya berbagai kasus moral yang membahayakan.

Salah satu krisis yang sangat menonjol pada dekade ini adalah budaya korupsi yang merupakan praktik pelanggaran moral dengan ditandai sifat-sifat ketidakjujuran, tidak adil, tidak bertanggung jawab, rendahnya disiplin, rendahnya komitmen kepada nilai-nilai moral dan kebaikan, hal mana menjadi penyebab utama negara Indonesia sulit untuk bangkit dari krisis Megawangi, 2009. ${ }^{2}$ Pada tahun-tahun terakhir ini, dua mega kasus korupsi yang menggoncang negara yaitu kasus Century Gate dan kasus Gayus Gate, hambalang, mahkamah institusi, migas. Disamping kasus korupsi dewan dan kepala pemerintahan daerah seperti kasus di banten yang menjadi komsumsi berita sehari-hari di media.

Hal ini menjadi indikasi bahwa kasus korupsi masih menjadi masalah utama di Indonesia, di samping kasus kriminal dan sadisme, seperti kasus pembunuhan sadis-berantai yang dilakukan oleh Jagal Ryan, preman-preman, munir dan kasus salah satu ketua KPK dan

1 Darmaningtyas. Pendidikan Pada Masa dan Setelah Krisis (Yogyakarta: Pustaka Pelajar, 2009 ). h. 19

2 Mengawangi, Pendidikan Karakter (Jakarta Indonesia haritage Fundation: 2002). 
lain-lainnya.

Ironinya, terjadinya maraknya demoralisme, radikalisme, vandalisme, plagiarisme, dan korupsisme, Nopotisme disisi lain pendidikan agama dan pendidikan moral Pancasila diberikan sejak pendidikan anak usia dini sampai perguruan tinggi, bahkan dalam konteks informal diberikan pula di tengah masyarakat dalam kehidupan sehari-hari. Lebih memprihatinkan bahwa para pelaku yang kontra karakter juga manusia yang rajin menjalankan ibadah agama. Sebagian pelaku kejahatan kadang berbungkus keagamaan, kasus sekolah Internasional di jakarta dan seperti kasus mutilasi karena ingin kesaktian-spiritual, merampok dan membunuh untuk keperluan jihad agama, dan melakukan penipuan dengan cara menjadi petugas haji, koperasi simpan pinjam uang, dana hibah. Ketika para pelaku kontra karantek ini diproses di kepolisian dan di pengadilan senantiasa menggunakan atribut-atribut agama.

Dengan kata lain, para pelaku kontra karakter ini atau pelaku kriminal ini bukan manusia yang tidak mengetahui sama sekali masalah moral, karaktek, dan keagamaan, bahkan ada yang menjadi panutan lokal keagamaan, seperti pemuka agama yang mencabuli pengikutnya, seperti ustad puji ustad guntur bumi atau menipu para pengikutnya dengan kemampuan menggandakan pengobatan secara gaib, dan berbagai kasus lainnya. Lebih ekstrim para pelaku mencari popularitas dengan mengaku sebagai Nabi baru atau menjadi malaikat yang diturunkan ke bumi, bahkan ada yang mengaku sebagai Tuhan.

Berdasarkan fakta-fakta yang diuraikan di atas, salah satu kebutuhan Indonesia ke depan adalah tampilnya kepemimpinan di berbagai sektor dan level yang berbasis akhlak atau karakter, dan juga di bidang pendidikan. Sebab kegagalan membangun karakter bangsa sekarang dan di masa depan secara langsung maupun tidak langsung merupakan kegagalan pendidikan.

\section{B. Pendidikan Berbasis Karakter}

Karakter merupakan sesuatu yang terlihat, yang terdiri dari sifat-sifat baik sebagai bentuk perilaku ahklak yang baik yang sesuai moral. Dengan kata lain, karakter merupakan bentuk perilaku konkrit atau perilaku yang telah diterapkan dengan mencerminkan nilai-nilai moral. Perwujudan perilaku yang terlihat dengan menunjukkan sifat-sifat baik sebagai ciri moral disebut sebagai karakter (Lickona, 2004). ${ }^{3}$ Tindakan yang tidak sesuai dengan moral, seperti tindakan merusak, tidak bertangungjawab, kejahatan, penggunaan narkoba, dan perilaku seksual pranikah adalah tindakan yang tidak berkarakter baik. Menurut Lickona (1996) untuk membentuk karakter yang baik, terdapat tiga bagian yang tidak terpisahkan, yaitu: (1) moral knowing (2) moral feeling; dan (3) moral action.

Indikator moral knowing antara lain: (1) kesadaran moral (moral awareness); (2) mengetahui nilai-nilai moral (knowing moral values); (3) mengambil sudut pandang orang lain (perspective-taking); (4) pemahaman makna moral (moral reasoning); (5) pengambilan keputusan berbasis moral (desicion-making); dan (6) mengenali diri sendiri (selfknowledge).

Indikator moral feeling antara lain: (1) hati nurani (conscience); (2) menghargai diri sendiri dan orang lain (self-esteem); (3) memahami kondisi emosional orang lain (empathy); (4) mencintai kebaikan (loving the good); (5) mengendalikan diri sendiri (self-control); (6) terbuka pada kebenaran dan menjaga perasaan (humility). ${ }^{4}$

Indikator moral action, antara lain: (1) kemampuan berfikir, berperasaan, dan bertindak moral (competence); (2) memiliki keinginan dan energi moral (will); dan (3) berkebiasaan (habit).

Kenapa moralitas di Indonesia terpuruk, padahal pendidikan agama dan moral Pancasila telah diajarkan? Apabila dikonfirmasi dengan teori Lickona, maka disadari bahwa posisi moral hanya berhenti pada moral knowing, artinya individu tahu moral baik dan berhenti pada kognitif, tetapi ketika bertindak baik (moral action) belum tercapai, sehingga aktivitas beribadah kepada Allah dijalankan, sekaligus melakukan pelanggaran terhadap larangan Allah. Banyak contoh, salah satunya, seorang pencopet yang tertangkap manakala diperiksa polisi, meminta ijin untuk shalat dan dia dalam keadaan berpuasa, ketika ditanyakan kenapa ahli ibadah ini melakukan keja-

3 Licona.T, Teaching Respeek and Responsibility (New york Touchstone Rookefeller Centre. 2004). h. 50

4 Ibid. h. 55 
hatan, jawabnya, profesi. ${ }^{5}$

Pendidikan moral atau pendidikan berkarakter merupakan usaha para pendidik melakukan berbagai usaha dalam mengatasi perilaku kurang baik pada para siswanya. Hampir semua sekolah atau madrasah memiliki aturan kedisiplinan atau tata tertib yang berbasis moral. Aturan ini tentu diiringi dengan reward and punishment.

Menurut Albertus (2010) pendidikan karakter yang efektif senantiasa menyertakan tiga basis pendekatan, yaitu pendidikan karakter berbasis kelas, kultur sekolah, dan komunitas. Pendekatan karakter berbasis kelas biasanya diwujudkan dalam integrasi kurikulum dan pembelajaran. Pendekatan kultur sekolah merupakan interaksi komunitas sekolah dengan keterikatan pada aturan norma, moral, dan etika bersama yang berlaku di sekolah. Sedangkan, pendekatan komunitas meruapakan interaksi sehari-hari anak didik dengan lingkungan keluarga dan masyarakat yang memelihara moralitas kehidupan. ${ }^{6}$

Inti dari pendidikan karakter adalah mengembangkan potensi anak didik sebagai pembelajar yang baik (good knower) yang selalu terikat dalam berfikir (fikir), merasakan (dzikir) dan bertindak (fi'il). Terhadap nilai-nilai kebaikan goodness. Lebih dari itu untuk lingkungan pendidikan Islam tentu menjadi basis spiritual - goodness yang biasanya dikenal di lingkungan pesantren, madrasah, diniyah, dan sekolah Islam dengan materi aqidah-akhlak. Bagaimana aqidahakhlak ini tidak hanya berhenti pada knowing, tapi juga menjadi feeling dan action. Strategi paling efektif adalah mengajar dengan "keteladanan dan inspirasi berbasis moral atau karakter".

\section{Kepemimpinan Berbasis Karakter}

1. Pengertian Kepemimpinan

Substansi kepemimpinan terdapat pada kata kunci "influence" yang berarti bahwa fungsi utama kepemimpinan adalah kemampuan mempengaruhi dirinya sendiri dan orang lain untuk mencapai tujuan kelompok yang dipimpinnya, baik berupa cita-cita, orientasi perjuan-

\footnotetext{
5 Ibid. h. 60
}

6 Albertus, DK, Pendidikan Karakter Intergral (dalam Koran harian kompas 11 pebruari 2010) gan, organisasi, atau komunitas yang melingkupi. Kepemimpinan dapat didefinisikan berdasarkan penerapannya pada bidang militer, olahraga, bisnis, pendidikan, industri dan bidang-bidang lainnya. Ordway Tead dalam Wursanto, ${ }^{7}$ memberikan rumusan "Leadership is the activity influencing people to cooperate some good which they come to find desirable". Kepemimpinan adalah suatu kegiatan mempengaruhi orang lain untuk bekerja sama guna mencapai tujuan tertentu yang diinginkan. Pakar lain, Santosa mendefinisikan kepemimpinan sebagai "usaha untuk mempengaruhi anggota kelompok agar mereka bersedia menyumbangkan kemampuannya lebih banyak dalam mencapai tujuan kelompok yang telah disepakati”. Sedangkan menurut Purwanto "kepemimpinan sebagai suatu bentuk persuasi, suatu seni pembinaan kelompok orang-orang tertentu, biasanya melalui 'human relations' dan motivasi yang tepat, sehingga tanpa adanya rasa takut mereka mau bekerjasama dan membanting tulang memahami dan mencapai segala apa yang menjadi tujuan-tujuan organisasi”. Menurut Goestch dan Davis "kepemimpinan merupakan kemampuan untuk membangkitkan semangat (morale) orang lain agar bersedia dan memiliki tanggung jawab total terhadap usaha mencapai atau melampaui tujuan organisasi”. Berdasarkan definisi para pakar di atas dapat dipahami bahwa kepemimpinan berujung pada kemampuan "mempengaruhi (influencing)" orang lain agar bekerjasama mencapai tujuan organisasi/institusi/ lembaga/jama'ah yang dipimpinnya.

Dalam Islam istilah kepemimpinan dikenal dengan kata Imamah (Arifin \& Slamet, 2009). ${ }^{8}$ Sedangkan kata yang terkait dengan kepemimpinan dan berkonotasi pemimpin dalam Islam ada tujuh macam, yaitu Khalifah, Malik, Wali, 'Amir dan Ra'in, Sultan, Rais, dan Ulil 'amri. Menurut Shihab Imam dan Khalifah, dua istilah yang digunakan Al-Qur'an untuk menunjuk pemimpin. Kata imam diambil dari kata amma - ya'ummu, yang berarti menuju, menumpu, dan meneladani. Kata Khalifah berakar dari kata khalafa yang pada mulanya berarti "di belakang". Kata khalifah sering diartikan "pengganti" karena yang menggatikan selalu berada di belakang, atau

\footnotetext{
7 Wursanto, Dasar-Dasar Ilmu Organisasi (Yogyakarta: Andi Ofset, 2012). h. 45
}

8 Arifin Selamet, Membangun Karakter Bangsa Melalui Kepememimpinan Moral Spritual (Jakarta: Pustaka Pelajar, 2010). h. 23 
datang sesudah yang digantikannya. Selanjutnya ia menyatakan bahwa Al-Qur'an menggunakan kedua istilah ini untuk menggambarkan ciri seorang pemimpin, ketika di depan menjadi panutan, dan ketika di belakang mendorong atau memotivasi, sekaligus mengikuti kehendak dan arah yang dituju oleh yang dipimpinnya. ${ }^{9}$

Secara teoretik kepemimpinan membicarakan bagaimana seseorang menjadi pemimpin, atau bagaimana timbulnya seorang pemimpin. Ada beberapa teori tentang kepemimpinan. Menurut Indrawijaya pada dasarnya ada dua teori kepemimpinan, yaitu teori sifat (traits theory) dan teori situasiaonal (situational theory), sementara Wursanto menyatakan ada enam teori kepemimpinan, yaitu; teori kelebihan, teori sifat, teori keturunan, teori kharismatik, teori bakat, dan teori sosial, ${ }^{10}$ sedangkan Thoha mengelompokannya kedalam; teori sifat, teori kelompok, teori situasional, model kepemimpinan kontiensi, dan teori jalan kecil-tujuan (path-goal theory). Pakar kepemimpinan dalam organisasi, Yukl, menambahkan pendekatan sosiokultural dengan tiga model, yaitu: kepemimpinan karismatik, transaksional, dan transformasional. ${ }^{11}$

\section{Kepemimpinan Pendidikan Berbasis Moral/Akhlak.}

Kepemimpinan pendidikan berbasis moral berorientasi pada kepemimpinan dalam konteks pendidikan yang mengutamakan dan memegang kuat aspek moralisme. Hal ini sesuai dengan spirit moral yang ditinjau asalnya dari bahasa Latin, yaitu kata mores, kemudian diterjemahkan menjadi "aturan kesusilaan", dalam bahasa Inggris berasal dari kata moral yang berarti standards of behavior atau principles of right and wrong Hornby.

Dalam bahasa sehari-hari, yang dimaksud dengan kesusilaan bukan mores, tetapi petunjuk-petunjuk untuk kehidupan sopan santun, dan tidak cabul. Jadi, moral adalah aturan kesusilaan, yang meliputi semua norma untuk kelakuan, perbuatan tingkah laku yang baik.

Moral merupakan pengetahuan yang menyangkut budi peker-

9 Quraish Shihab Wawasan Al-Qur'an (Bandung: Mizan, 2000). h.103

10 Wursanto, Dasar-dasar Ilmu Organisasi (Yogyakarta: Andi Offset, 2012). h. 97

11 Yukl, Model-Model Kepemimpinan (Jakarta: Media Press, 2001). h.72 ti manusia yang beradab. Moral juga berarti ajaran yang baik dan buruk perbuatan, dan kelakuan (akhlak). Moralisasi, berarti uraian (pandangan, ajaran) tentang perbuatan dan kelakukan yang baik. Sebaliknya perbuatan yang mengindikasikan kerusakan moral disebut demoralisasi. Moral juga dapat dibedakan menjadi dua macam, yaitu: (1) Moral murni, yaitu moral yang terdapat pada setiap manusia, sebagai suatu pengejawantahan dari pancaran Ilahi. Moral murni disebut juga hati nurani; (2) Moral terapan, adalah moral yang didapat dari ajaran pelbagai ajaran filosofis, agama, adat yang menguasai pemutaran manusia. ${ }^{12}$

Selanjutnya, Sumaryono mengemukakan tiga faktor penentu moralitas perbuatan manusia yaitu : motivasi, tujuan akhir, dan lingkungan perbuatan. Moralitas adalah kualitas perbuatan manusiawi, sehingga perbuatan itu dinyatakan baik atau buruk, benar atau salah. Moral sendiri menurut Sumaryono dibagi menjadi dua bagian yaitu: moralitas intrinsik dan ekstrinsik. ${ }^{13}$

Moralitas intrinsik (intrinsic morality) menentukan perbuatan itu benar atau salah berdasarkan hakikatnya, terlepas dari pengaruh hukum positif. Artinya penentuan benar atau salah perbuatan tidak tergantung pada perintah atau larangan hukum positif. Misalnya, warga satu RT melakukan gotong royong membersihkan lingkungan tempat tinggal atau selalu bermuka ramah dan memberikan yang terbaik bagi sesama.

Moralitas ekstrinsik (extrinsic morality) menentukan perbuatan itu benar atau salah sesuai dengan sifatnya sebagai perintah atau larangan dalam hukum positif. Misalnya: (1) Larangan menggugurkan kandungan; (2) larangan melakukan pencurian, penipuan, perampokan, dan pemerkosaan; atau hal-hal lain yang diatur dalam KUHP, UU, dan produk hukum positif lainnya.

Moral dalam perspektif ajaran Islam dikenal sebagai akhlak, oleh karena pembahasan moral di sini lebih ditekankan pada pengertian akhlak, sebagaimana diungkapkan oleh Al-Ghazali bahwa akhlak adalah keadaan batin yang menjadi sumber lahirnya perbuatan yang muncul secara spontan tanpa memperhitungkan untung

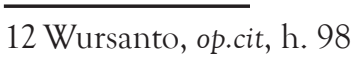

13 Sumaryono, Kepemimpinan Dalam Manajemen Organisasi (Jakarta: Media Prees 2002). h. 108 
dan rugi. Menurut Syihab (2002) kata "Akhlak" diambil dari bahasa Arab yang biasa diartikan tabi'at, perangai, kebiasaan bahkan agama. ${ }^{14}$ Dalam Kamus Besar Bahasa Indonesia (1987 M) kata "Akhlak" diartikan sebagai budi pekerti atau kelakuan. Akhlak yang baik atau buruk tergantung dan bermula dari hatinya (qalbu), sebagaimana sabda Rasulullah Saw,

"Ingatlah bahwa dalam tubuh (manusia) ada segumpal darah (lamudghotan) yang apabila ia baik maka baiklah seluruh tubuh (nya), dan bila ia buruk maka buruk pula seluruh (perbuatan) tubuh, ingatlah dia itu adalah hati (al qalbu)." (al-Hadits). Qalbu yang buruk atau tercela adalah qalbu yang berpenyakit yang awalnya diibaratkan sebuah noda atau titik kecil, penyakit itu datang pada qalbu melalui interaksi sosial kehidupan manusia, akibat lemah atau tidak kontrol dan tidak adanya filter dari manusia yang menggunakan mudghah tersebut, dia akan terus bersemayam pada qalbu.

Sebagaimana firman Allah SWT dalam al-Qur'an:

"Sekali-kali tidak (demikian), sebenarnya apa yang selalu mereka usahakan itu menutup hati mereka." (Q.S. al-Muthafifin:14)

Penyakit hati yang tidak segera diobati, maka noda hitam (penyakit hati) itu akan terus membesar dan berkembang sampai menutupi seluruh qalbunya menjadi hitam legam, sehingga tidak mampu lagi menerima dan memantulkan cahaya kebenaran (cahaya Ilahi) sebagaimana digambarkan dalam al-Qur'an:

"Dalam hati mereka ada penyakit, lalu Allah menambah penyakitnya; dan bagi mereka siksa yang pedih, disebabkan mereka berdusta." (Q. S. Al-Baqarah: 10).

Dapat dimaknai sebagai perlawanam terhadap tuntunan ajaran kebenaran yang bersumber dari wahyu Allah secara qoth'i (jelas) maupun dhany (samar), dalam praktiknya seperti mengambil hak orang lain, menghina orang lain, melakukan ketidak jujuran dalam penilaian kinerja bawahan, melakukan manipulasi data dalam pelaporan keuangan (in-accountable), dan banyak lagi sampai pada puncaknya penolakan tehadap kebenaran yang biasanya dimulai dari pembiasan kebenaran kecil-kecilan secara bertahap.

Masalah hati yang baik dan buruk, dalam pandangan Islam

14 Quraish Shihab, Wawsan Al-Qur'an, h. 104. dibagi menjadi empat kelompok, yaitu hati yang iman, hati yang kafir, hati yang munafik, dan hati yang fasik. Keempat kuadran ini diderivasi dari sabda Rasulullah Saw berikut:

"Dari Ali bin Abi Thalib r.a., Rasulullah Saw bersabda: 'hati itu ada empat macam, pertama, hati yang terang bersinar penuh cahaya yaitu hatinya orang yang beriman, kedua, hati yang tertutup yaitu hati orang kafir, ketiga, hati yang terbungkus yaitu hati orang munafik, dan keempat hati yang memiliki dua macam benih keimanan dan kemunafikan, yaitu hatinya kelompok manusia fasik yang mencampurkanadukan kebaikan dan keburukan." (al-Hadits).

Kepemimpinan pendidikan pada dasarnya merupakan kepemimpinan hati, mendidik dengan hati nurani (conscience), tulus ikhlas, hati yang selalu positif dan dipenuhi rasa pengabdian kepada tuhan-Nya, dan selalu ingin menegakkan moralita dalam koteks pendidikan yang dipimpinnya.

\section{Kepemimpinan Pendidikan Berbasis Spiritual}

Kepemimpinan pendidikan berbasis spiritual merupakan kepemimpinan dalam pendidikan yang bersifat trasendental, sebagaimana kepemimpinan kenabian (prophetic leadership). Nabi Muhammad Saw mendidik keluarga dan para shahabat melalui dimensi spiritual, dalam kepemimpinannya senantiasa menginspirasikan arah keterdidikan melalui informasi ilahiyat sebagaimana yang disitir dalam alQur'an:

"Tiadalah dia (Muhammad) berkata-kata, kecuali wahyu dari-Nya (Allah).”

Spiritual dalam bahasa Inggris berasal dari kata "spirit" yang berarti jiwa, arwah, roh, soul, semangat, moral, dan tujuan atau makna yang hakiki. Sedangkan dalam bahasa Arab, istilah spiritual terkait dengan yang ruhani wa ma'nawi dari segala sesuatu (Tobroni, 2005). Makna inti dari kata spirit berikut kata jadiannya seperti spiritual, spirituality adalah bermuara kepada kehakikian, keabadian, dan ruh; bukan yang sifatnya sementara atau tiruan. ${ }^{15}$

Menurut Tobroni dimensi spiritual senantiasa berkaitan langsung dengan realitas Tuhan Yang Maha Kuasa, Spiritualitas bukan

15 Tobroni, The Spritual Leadership (Malang: UMM Press, 2012). h. 109 
sesuatu yang asing bagi manusia, karena merupakan inti (core) kemanusiaan itu sendiri. Manusia pada dasarnya terdiri dari unsur material dan spiritual dalam bahasa Arab disebut unsur jasmaniyah wa ruhaniyah. Perilaku manusia merupakan produk tarik-menarik antara energi spiritual dan material. ${ }^{16}$

Dorongan spiritual senantiasa membuat kemungkinan membawa dimensi material manusia kepada dimensi spiritual (semangat ruh dan ilahiyah). Strateginya dengan memahami dan menginternalisasi sifat-sifat-Nya, asma-asma-Nya, menjalani kehidupan sesuai dengan petunjukNya dan meneladani Rasul-Nya. Tujuannya memperoleh ridlo-Nya, menjadi hambah-Nya, sahabat-Nya, dan bahkan kekasih-Nya. Inilah yang dicontohkan Nabi Muhammad Saw sebagai insan kamil, yang keberadaannya membawa rahmat dan kebahagiaan dunia-akhirat bagi manusia yang lainnya.

"Sungguh dalam diri Rasulullah (Muhamamad Saw) terdapat teladan terbaik (al-uswat al-hasanah)." (Q.S. al-Ahdzab)

\section{Implementasi Kepemimpinan Pendidikan Berbasis Karakter}

Berdasarkan pengertian tentang kepemimpinan pendidikan, karakter, moral/akhlak, dan spiritual, maka dapat dipahami bahwa kepemimpinan pendidikan yang berbasis karakter equal dengan kepemimpinan pendidikan berbasis moral-spiritual yaitu kepemimpinan pendidikan yang mengedepankan nilai-nilai moral atau akhlak, dengan menambahkan arah dimensi keduniawian menuju kepada dimensi spiritual atau keilahian. Allah sebagai Tuhan adalah pengilham bagai pemimpin sejati, mencerahkan, membersihkan hati nurani dan menenangkan jiwa-jiwa hamba-Nya dengan cara yang sangat bijaksana melalui pendekatan etis dan keteladanan. Oleh karena itu Tobroni menyatakan bahwa kepemimpinan pendidikan yang berbasis spiritual disebut juga sebagai kepemimpinan pendidikan yang berdasarkan etika religius. ${ }^{17}$

Tobroni mendefinisikan bahwa kepemimpinan (pendidikan) spiritual merupakan kepemimpinan yang mampu mengilhami, membangkitkan, mempengaruhi, dan menggerakkan para pengikut-

16 Tobroni, .h.150

17 Ibid. h. 159 nya melalui keteladanan, pelayanan, kasih sayang, dan implementasi nilai-nilai dan sifat-sifat ketuhanan lainnya dalam tujuan, proses, budaya, dan perilaku kepemimpinan. ${ }^{18}$

Kepemimpinan pendidikan berbasis moral-spiritual dalam perspektif kajian sejarah Islam, dapat merujuk kepada pola kepemimpinan yang diterapkan oleh Nabi Muhammad Saw. Dengan integritasnya yang luar biasa, Nabi Muhammad Saw memperoleh gelar al-Amin (orang yang terpercaya). Hart, penulis buku "Seratus Tokoh yang Paling Berpengaruh dalam Sejarah" telah menempatkan Nabi Muhammad Saw diurutan pertama dan menulis: "Muhammad mampu mengembangkan kepemimpinan (pendidikan) yang paling ideal dan paling sukses dalam sejarah peradaban umat manusia.” 19

Widjayakusuma dan Yusanto, telah mencatat empat sifat yang utama dalam kepemimpinan Nabi Muhammad Saw, yaitu: Siddiq (righteous), amanah (trustworthy), fathanah (working smart), dan tabligh (communicate openly). Melalui keempat sifat utama inilah Nabi $\mathrm{Mu}$ hammad Saw mampu mempengaruhi orang lain dengan cara mengilhami tanpa mengindoktrinasi, menyadarkan tanpa menyakiti, membangkitkan tanpa memaksa, dan mengajak tanpa memerintah. ${ }^{20}$

Menurut Tobroni, kepemimpinan moral spiritual semakin diterima pada abad ke-21, yang dikatakan oleh futurolog Aburdene dan Fukuyama sebagai abad nilai atau the value age. Dalam perspektif sejarah Islam, kepemimpinan moral spiritual yang dicontohkan Nabi Muhammad Saw telah terbukti menjadi kekuatan yang luar biasa untuk menciptakan individu-individu yang tidak hanya berkomitmen terhadap moralitas kehidupan tetapi juga membangun pribadi-pribadi yang suci, memiliki integritas dan budi pekerti yang baik (akhlaq al-karimah) yang keberadaannya bermanfaat dan membawa kegembiraan kepada yang lain. Secara sosial moral-spiritual mampu membangun masyarakat Islam dan Islami yang mencapai puncak peradaban dan mampu mencapai predikat umat terbaik (khaira ummat) dan keberadaannya membawa kebahagiaan untuk seluruh 18 Ibid. h. 160.

19 Hart, Seratus Tokoh yang Paling Berpengaruh dalam Sejarah (Jakarta: Pustaka Jaya, 1997). h. 88

20 Wijaya Kusuma Yustanto, Pengantar Manajemen Syariat, (Jakarta: Kairul Bayan, 2012). h. 110 
kehidupan (rahmatan li al-alamin), artinya bukan hanya untuk umat Islam saja tetapi juga bagi seluruh umat manusia apapun agama dan keyakinannya, juga bagi alam semesta. ${ }^{21}$

Pemimpin pendidikan berbasis moral-spiritual tentu harus memiliki konsep pilihan bagi kepemimpinannya, antara pilihan jalan Allah ( $f$ i sabilillah), dan nilai-nilai lain yang semakin jauh dari nilai keilahian. Tobroni dalam disertasinya telah membuat model pilihan nilai-nilai berbasis moral-spiritual dengan nilai-nilai material sekuler yang tidak didasari sama sekali dengan nilai-nilai spiritual. ${ }^{22}$

\section{E. Penutup}

Ketika bangsa Indonesia sedang menghadapi krisis multi dimensi yang didalamnya terjadi kemerosotan nilai-nilai moral, nilainilai keadilan, nilai-nilai kemanusiaan, dan nilai-nilai spiritual, sebagai akibat dari adanya ethical malaise atau ethical crisis. Drucker (1990) menyatakan bahwa bahaya kehidupan yang dihadapi oleh semua bangsa adalah lahirnya masyarakat barbar yang terdidik, Darmaningtyas menyebutnya pelaku kejahatan yang intelek dengan sebutan preman berdasi, artinya para pelaku kriminal yang terpelajar. ${ }^{23}$ Kanungo dan Mendocca (1996) juga mengatakan bahwa masyarakat telah kehilangan kepercayaan akan nilai-nilai dasar ekonomi, dan karena itu perlu kelahiran kembali moral-spiritualitas dalam kepemimpinan dan pendidikan. ${ }^{24}$

Sejalan antara ungkapan para ahli dengan kondisi riel keterpurukan akhlak di Indonesia, terutama kasus korupsi yang masih menjadi momok bagi bangsa dan calon generasi bangsa, sehingga bangsa Indonesia sekarang dan di masa depan membutuhkan pembangunan karakter (character building) dalam pendidikan dan kepemimpinan atau kepemimpinan pendidikan dengan diimbangi pendidikan berciri karakter dan kepemimpinan berbasis moral-spiritual

\section{Tobrani, Op cit. h.170}

\section{Ibid. h.178}

23 Darmanningtyas, Pendidikan Pada Masa dan Setelah Krisis (Yogyakarta: Pustaka Pelajar, 2009). h. 121.

24 Kanungo, RN. Mondoncca, Ethical Dimension of Leadeship (London: Sage, 1996). h.195. dari yang tertinggi sampai dengan terendah. Karakter yang tidak baik dapat dilakukan oleh oknum yang tertinggi diwakili oleh pejabat negara, para dewan, bahkan ada di jajaran KPK, sedangkan yang terendah dapat dikaji dari kasus ketua RT yang dibunuh di Sumatera karena jatah raskin untuk rakyat miskin, banyak dialokasikan untuk saudara-saudaranya sendiri, ada yang marah dan berujung pada pembunuhan. Belum lagi keputusan pengadilan yang seringkali dinilai tidak adil, seperti ketimpangan hukuman bagi koruptor kelas kakap dengan pencari 1 buah semangka di kebun.

Dari uraian ini dapat dipahami bahwa membentuk bangsa yang berkarakter tentu efektif bilamana diberikan pada konteks pendidikan, baik di sekolah, kultur sekolah, maupun komu nitas luas, demikian pula dengan seorang pemimpin pendidikan yang basis moral-spiritual. Akan mampu menumbuhkan dalam kepemimpinannya kesalehan individu, sehingga pemimpin akan menjadi pribadi yang saleh yang senantiasa menunjukkan sinergitas antara dzikir (hati), fikir (intelektual), dan fi'il (perilaku). Tentu proses pertama yang harus dilakukan pemimpin pendidikan adalah memahami nilai-nilai moral-spiritual, kemudian melakukan internalisasi diri terhadap nilai-nilai tersebut. Pada tahap berikutnya perlu melakukan proses sosialisasi (socialization process) nilai-nilai moral-spiritual dengan keteladanan dan inspiring melalui proses pendidikan. Pada tahap inilah pemimpin menumbuhkan kesalehan sosial. Tahap terakhir, yang dilakukan seorang pemimpin pendidikan adalah menumbuhkan budaya pendidikan berbasis moral-spiritual sebagai suatu habits, culture, dan climate. Jika ketiga tahap ini mampu dibangun oleh pemimpin pendidikan, maka pembangunan karakter bangsa dapat diwujudkan, melalui pendidikan formal, nonformal, dan informal yang dimulai dari diri sendiri, lingkungan sosial, sampai budaya sosial. Dengan sendirinya akan tercipta lingkungan berkarakter, lingkungan beradab, lingkungan yang anti KKN dan sumber kejahatan atau kerusakan, lingkungan yang tidak ada cahaya ilahi, dengan kata lain, lingkungan pendidikan kondusif yang berbudaya dan berkkter madani. 


\section{Daftar Pustaka}

Albertus, D.K. (2010). Pendidikan Karakter Integral. Dalam Koran Harian KOMPAS, 11 Pebruari

Abdurrahman, M. (2002). Dinamika Masyarakat Islam (dalam Wawasan Fikih), Bandung: Remaja Rosdakarya

Arifin, I. 2010. Membangun Karakter Bangsa Melalui Kepemimpinan Moral Spiritual: Strategi Atasi Kasus Demoralisasi dan Korupsi di Indonesia. Makalah konferensi dan workshop nasional 16-17 Oktober 2010 dalam Proceeding. Malang: Jurusan Psikologi Fakultas Ilmu Pendidikan Universitas Negeri Malang

Baharuddin, \& Umiarso. 2012. Kepemimpinan Pendidikan Islam:Antara Teori dan Praktek. Jogjakarta: Ar-Ruzz Media.

Blumberg, A., \& Greenfield, W. 2002. The Effective Principal: Perspectives on School Leadership. 3th Edition. Boston: Allyn and Bacon, Inc

Champbell, R.F., Corbally, J.E., \& Nystrand, R.O. 2003. Introduction to Educational Administration. 6th Edition. Boston: Allyn and Bacon, Inc.

Darmaningtyas (2009). Pendidikan pada Masa dan Setelah Krisis. Yogyakarta: Pustaka Pelajar

.Drucker, P. (1990). Managing the Non-Profit Organization. New York: Harper Collins.

Hornby, H. (1995). Oxford Advance Learner Dictionary. Oxford: Oxford University Press.

Indrajaya, A. I. (1983). Perilaku Organisasi, Bandung: Sinar Baru.

Hart, M.H. (1994). Seratus Tokoh yang Paling Berpengaruh dalam Sejarah. Jakarta: Pustaka Jaya.

Kanungo, R.N., \& Mondonca, M. (1996). Ethical Dimension of Leadership. London: SAGE

Lickona, T. 1996. Teaching Respect and Responsibility. Reclaiming Children and Youth.Newyork

Megawangi, R. (2009). Pendidikan Karakter. Jakarta: Indonesia Heritage Foundation.

Muhammad, H. (2002). Dialog antara Tasawuf dan Psikologi, Yogya- karta: Walisongo Press dan Pustaka Pelajar.

Mubarok, A. (2003). Sunnatullah dalam Jiwa Manusia, Jakarta: IIIT Indonesia

Moedjiono, I. (2002). Kepemimpinan dan Keorganisasian, Yogyakarta: UII Press.

Nasr, S.H. (2002). Ensiklopedi Tematis Spiritualitas Islam. Bandung: Mizan

Rahmat, J. (1997). Renungan-Renungan Sufistik, Bandung: Mizan.

Riawan, A. A, (2004). The Celestial Management, Jakarta: Senayan Abadai Publishing.

Ruslan, A. (2010) Sallis, Edward, (1993). Total Quality Management in Education, Philadelphia, London

Shihab, M.Q. (2000). Wawasan Al-Qur'an, Bandung: Mizan.

Thoha, M. (2003). Kepemimpinan Dalam Manajemen, Jakarta: Raja Grafindo Persada.

Tjahjono, H. (2003). Kepemimpinan Dimensi Ke Empat. Jakarta: Elexmedia Computindo.

Tobroni (2005). The Spiritual Leadership. Malang: UMM Press.

Tjiptono \& Anastasia, D. (2001). Total Quality Management, Yogyakarta: Andi.

Widjajakusuma, M.K., \& Yusanto, M.I. (2003). Pengantar Manajemen Syariat. Jakarta: Kairul Bayan

Wursanto. (2002). Dasar-Dasar Ilmu Organisasi, Yogyakarta: Andi. April 17th, 2014 | Category: 